\title{
PRAGMATIC TRANSFER IN APOLOGY EMPLOYED BY ENGLISH EDUCATION STUDENTS OF ISLAMIC STATE UNIVERSITY (UIN) RADEN FATAH
}

\author{
Tiara Eliza \\ English Education Study Program, Faculty of Economy, Palembang University, Indonesia \\ E-mail: tiaraeliza90@gmail.com
}

\begin{abstract}
APA Citation: Eliza, T. (2019). Pragmatic transfer in apology employed by English education students of Islamic state university (UIN) Raden Fatah. English Review: Journal of English Education, 7(2), 151-158. doi: 10.25134/erjee.v7i2.1631.
\end{abstract}

Received: 23-01-2019

Accepted: 26-04-2019

Published: 01-06-2019

\begin{abstract}
This study intends to find out and to describe apology strategies made by the sixth and eighth semester students of English Education Study Program of Islamic State University (UIN) Raden Fatah Palembang, and to explain how the pragmatic transfer interferes the apology strategies. This study used a qualitative descriptive design. Written discourse completion tasks and observation by doing a role play were used as the instruments to obtain the data. There were 66 students selected as the subjects of study. The data obtained were analyzed based on the classification of apology strategy proposed by Olshtain and Cohen (1983). As result, it was found that there were five apology strategies made by the students, for example, using the word 'sorry' to express 'regret' was considered the most frequently used strategy. Then, the result also showed that the speakers who have low social status tend to use polite strategy in all levels of social relationships (strangers and acquaintances). For the speakers who have high social status and equal tend to use less polite and casual expressions, respectively. Moreover, some students use some pragmatic transfers in expressing apology strategies influenced by their L1 (mother tongue) or L2 (Indonesian) culture.
\end{abstract}

Keywords: apology strategies; interlanguage; pragmatics; pragmatic transfer; speech act.

\section{INTRODUCTION}

Apology plays an important role in community as human beings live in a social group. Apology is a fundamental speech act which is part of human communication that occurs in every culture to maintain good relations between interlocutors (Brown \& Levinson, 1987; Olshtain \& Cohen, 1983). Thus, an apology is a compensatory action for the offense that has been done by someone in order to maintain social harmony among the speaker and hearer. Apology is one of the most frequently used expressing among the speech acts employed in daily communication (Qorina, 2012). Then, if it refers to the apology terms in Indonesian, the expressions of apology tend to make a request for forgiveness. That is why, the term of 'I apologize' do not exist. Expressions of regret exist, but are not generally used for apologizing (Wouk, 2006).

Moreover, sometimes, there is a repetition in expressing apology used by Indonesian. It means that they repeat their apology expressions to emphasize their offense, hence, reducing threat on the hearer and hopefully making their expression can be received by the hearer (Syahri \& Kadarisman, 2007). For example, (1) please forgive me, I did not attend to your party yesterday. I have something to do. Once again forgive me. (2) Sorry, my friend. I do not come to your birthday party. Once again I beg your forgiveness. The repetition shows the regret to their offense, so that is why they repeat it in order to get the hearer's forgiveness and show a kind of speaker's politeness as an offender. It is assumed that if they minimize the cost to the Hearers, the requests for forgiveness will probably be fulfilled. The Speakers attempt to minimize the cost to Hearers by repeating apology expressions or at least reducing the unexpected consequences from their offense (Wouk, 2006). If it refers to target language culture, there was no repeating in expressing their regrets. Those transfers have occurred by the effects of social conditions in language using.

In this case, apology strategies are obviously significant in social life to get an excuse for any inappropriate action done. There are a number of strategies that the apologizer chooses to perform an apology. Goffman (1971) states that for an apology to be successful, the apologizer has to consider three factors: acknowledging of an offense, taking responsibility for the offense, and offering compensation. In order to know how to express apology appropriately, the speakers must 
have pragmatic competence to understand what they are talking about in order to make the interaction successful. Moreover, Moghaddam (2012) states a learner having good grammatical competence may not be pragmatically competent in communication. Sometimes, there is misunderstanding that occurs among the learners. They are sometimes not able to understand the utterances pragmatically. Thus, to avoid misinterpreting, pragmatics plays an important role. That is why pragmatics is indispensable to be taught.

Further, some second/foreign language learners have been claimed to make errors in using speech acts to communicate with native speakers of the target language because of the complexity of speech acts since they are conditioned by social, cultural, situational and personal factors (Cohen \& Olshtain, 1993). Related to this, since English is a foreign language in Indonesia, the speakers/learners generally apply the rules of their L1 when they speak in L2. Hence, the result is communication breakdown or communication conflict occurs (Istifci, 2009). The problem which occurs in their communication is called a negative transfer from L1 to L2 when they speak in English. Then, to solve this problem the learners must know the social and culture in L1 and L2. That may make the learners aware and familiar with how they should understand the meaning of the utterance or expression, and social cultural aspect of L2 based on its context and function. Hence, pragmatic transfer takes an important role in this study. It facilitates the students to learn cross cultural understanding and cultural norms in English context.

Pragmatic transfer is the way to produce the utterances in L1 which is not applied sufficiently in producing utterances in L2. In this case, the learners tend to transfer their native social and cultural norms into the target language $(\mathrm{Bu}$, 2012). In line with this, Franch (1998) states that pragmatic transfer refers to the influence of the first language (L1) in communication when the speakers use L2. Transfer occurs in two ways: 1) negative transfer or interference occurs when the two languages do not share the same language system, resulting in the productions of errors, and 2) positive transfer or facilitation, when the two languages share the same language system and the target form is correctly transferred. Related to this, interlanguage takes an important part in this study. Interlanguage can be defined as the type of language produced by second and foreign language learners who are in the process of learning a language (Richards \& Sukwiwat, 1983) as cited in (Franch, 1998). By discussing apology speech act realization in interlanguage pragmatics, it is positive for teacher to facilitate the students to learn cross cultural understanding and cultural norms in English context, such as how English native speakers perform apology in various context and situations, so it can help them to communicate in English appropriately and naturally.

Most of research in pragmatics has investigated the speech act of apology in different languages employed by native and nonnative speaker (Olshtain \& Cohen, 1983; Sugimoto, 1998; Nureeden, 2007; Jebahi, 2011; Tamimi Sa'ad \& Mohammadi, 2014; Syahri \& Kadarisman, 2007). Related to this, the writer investigated pragmatic transfer potentially occurs due to cultural or language differences. That is, the transfer occurs due to the norms derived from their native cultures. Therefore, this study aims at explaining how the pragmatic transfer interfere the apology strategies and finding out the apology strategies of English Education students as EFL learners. This study employed the apology strategies provided by Olshtain and Cohen (1983) as cited in Ellis (2012). There were five categories of the apology strategies. In the first category is divided into three sub strategies while the second category is divided into four sub strategies.

1) An Illocutionary Force Indicating Device (IFID).

a. An expression of regret. E.g. I'm sorry

b. An offer of apology. E.g. I apologize

c. A request for forgiveness. E.g. Excuse me

2) An expression of the speaker's responsibility for the offense.

a. Explicit self-blame.

b. Lack of intent.

c. Expression of self-deficiency.

d. Recognizing the other person as deserving apology

3) Explanation or Account. E.g. I was trapped in the traffic jam.

4) An offer of repair. E.g. I'll pay for the damage.

5) A promise of forbearance. E.g. It won't happen again.

\section{METHOD}

The study used a qualitative analytical method. It was indicated by the characteristics of the techniques of collecting and analyzing the data. 
The subjects of this study were the students of English Education Study Program of Islamic State University (UIN) Raden Fatah Palembang. They were at the $6^{\text {th }}$ and $8^{\text {th }}$ semesters in academic year of 2013/2014. There were sixty six students selected as the subjects of study, thirty five students are in the sixth semester and thirty one are in the eighth semester. There were two types of instruments used in collecting data. The first was Discourse Completion Test (DCT). Gass and Slinker (2001) stated that the DCT had been used in a number of studies to gather data for native and non-native speakers concerning particular speech acts (apologies, compliments, refusal, request etc). That is a set of written questionnaire accompanied by brief situational descriptions. The DCT used for this study consisted of 25 apologizing situations which were adapted from Tuncel (2011) and distributed to the samples. Since there were 25 apologizing situations, it was observed in 25 times.

The second instrument was observation by using a role play. There were 40 students (20 students for each semester and they were divided into 10 pairs) was selected as the participants for the role-plays. They were asked to produce dialogues based on the scenarios written in the role-plays. The scenarios were taken from DCT Questionnaire. The procedures were conducted carefully to maintain continuous participation of all the participants. In order to prevent repeating other participants' utterances, the researcher put each scenario on a piece of paper and rolled the papers into coupons. They were given opportunities to take two coupons randomly and produce dialogues in front of the class with their fellow students. They practiced the role-play in pairs. These stages were done several times in several meetings until every subject played the scenarios provided, it depends on the student. As a result, there were 40 dialogues that were recorded and transcribed.

In analyzing the data, firstly, the participants' responses were identified and then coded according to the strategies adopted from Olshtain and Cohen (1983) as cited in Ellis (2012). Secondly, the researcher identifies the development strategies used by the students. After that, the researcher identifies the context of pragmatic transfer in expressing apology. The data were then tabulated based on the classification and were interpreted. Finally, the conclusion was drawn based on the findings.

\section{RESULTS AND DISCUSSION}

It was found that the respondents use many strategies in expressing their apology, such as an expression of regret, a request for forgiveness, explanation, and offering repair.

Table 1. The frequency of the occurrences of apology strategies in DCT questionnaire

\begin{tabular}{lcccc}
\hline \multicolumn{1}{c}{ Apology Strategies } & Frequency & Percent & $\begin{array}{c}\text { Valid } \\
\text { Percent }\end{array}$ & $\begin{array}{c}\text { Cumulative } \\
\text { Percent }\end{array}$ \\
\hline An expression of regret (1a) & 386 & 27.8 & 27.8 & 27.8 \\
An offer of apology (1b) & 27 & 1.9 & 1.9 & 29.8 \\
A request for forgiveness (1c) & 85 & 6.1 & 6.1 & 35.9 \\
Explicit self blame (2a) & 39 & 2.8 & 2.8 & 38.7 \\
Lack of intent (2b) & 75 & 5.4 & 5.4 & 44.1 \\
Expression of self- deficiency (2c) & 246 & 17.7 & 17.7 & 61.8 \\
Recognizing the other person as deserving & 5 & 4 & 4 & 62.2 \\
apology (2d) & & & & \\
Explanation or Account (3) & 277 & 20.0 & 20.0 & 82.1 \\
Offer of repair (4) & 217 & 15.6 & 15.6 & 97.8 \\
Promise of forbearance (5) & 31 & 2.2 & 2.2 & 100.0 \\
Total & 1388 & 100.0 & 100.0 & \\
\hline
\end{tabular}

Table 1 presents the total percentage of apology strategies used by the participants. The result reveals that an expression of regret is the most frequent apology strategy used with total of
386 (27.8\%). Expression of deficiency and explanation are the other strategies which are used extensively (from 17.7 to $20 \%$ ). No other strategy is found for more than $27 \%$ of the data.

\begin{tabular}{ccccc}
\multicolumn{2}{c}{ Table 2. The frequency of the occurrences of apology strategies in role play } \\
\hline Apology Strategies & Frequency & Percent & $\begin{array}{c}\text { Valid } \\
\text { Percent }\end{array}$ & $\begin{array}{c}\text { Cumulative } \\
\text { Percent }\end{array}$ \\
\hline An expression of regret(1a) & 1 & 2.5 & 2.5 & 2.5
\end{tabular}

1

2.5 


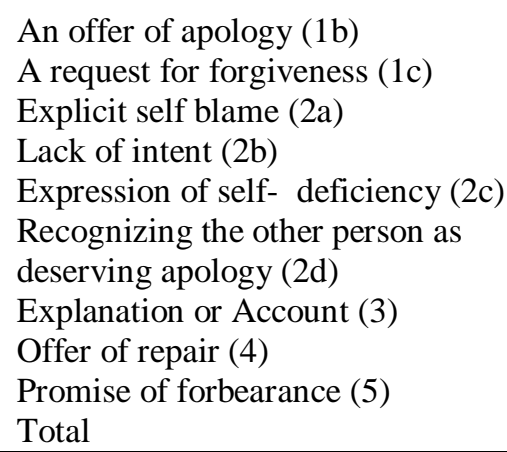

Table 3 shows the total percentage of apology strategies in all situations by using Role play. The result reveals that there are differences between the total percentage of apology strategies by using DCT and Role Play. An explicit expression of apology, particularly the strategy of explanation or account, is the most frequent apology strategy used with total of 19 $(47.5 \%)$. Expression of self-deficiency and Offer of repair strategies are the other strategies which are used extensively $(12.5 \%)$. No other strategy is found for more than $47 \%$ of the data.

The followings are the analysis and discussion of the strategies and expressions used by the sample students.

\section{Explanation or account}

It is an expression that gives a reason of the cause of the offense. In other words, the speaker explains why violation or damage happened. It shows that justifying the offense by explaining the reason.

Situation 25: Coming late at friend's birthday party (8) I am sorry darling. I was late because of traffic jam.

There are some factors that need to be considered in analyzing discourses or expression used in society, namely, age, gender, time, place, and social status which is divided into three levels: high, equal and low (Holmes, 1989), and social distance which is divided into three levels: stranger, acquaintance, and intimate (Brown \& Levinson, 1987).

This situation explained that a speaker invited to come to his/her friend birthday dinner at a restaurant but s/he was late. This situation took place at a restaurant. It was used by the speakers because the speaker had equal social status. Beside social status, the aspects of social distance also have influenced the speaker in using that expression because the speaker uses the word "darling". It is a kind of endearment expression which indicates that the speaker has known the hearer well. Thus, they are intimates

\begin{tabular}{cccc}
0 & 0 & 0 & 0 \\
2 & 5.0 & 5.0 & 7.5 \\
2 & 5.0 & 5.0 & 12.5 \\
0 & 0 & 0 & 0 \\
8 & 20.0 & 20.0 & 32.5 \\
0 & 0 & 0 & 0 \\
& & & \\
19 & 47.5 & 47.5 & 80.0 \\
5 & 12.5 & 12.5 & 92.5 \\
3 & 7.5 & 7.5 & 100.0 \\
40 & 100.0 & 100.0 & \\
\hline
\end{tabular}

in terms of social distance. The endearment markers are often used when the speaker and hearer have close relationship in terms of social distance. In the aspects of age, they are in the same age as friends. Then, the aspects of gender and time are not known in this context. Furthermore, at the end of this utterance, the speaker says the reason why he/she comes late. In this case, the speaker does not only express his/her intimacy but also an explanation for the offense. It indicates that the speaker does not intend to come late. The speaker embedded his/her apology expression with utterances aiming to minimize hearer's wrathfulness because of the speaker's carelessness.

\section{Expression of self-deficiency}

It indicates that the offender attributes the reason of the offense to herself/himself, such as I was confused, I was not thinking, I forgot, etc.

Situation 1: A speaker forgets to get-together with a friend. The speaker calls him to apologize. This is the second time the speaker forgot such a meeting.

(15) I am sorry, I really forget to our meeting (16) I am so sorry darling, I really forget to inform you, actually I have promised with my mom to accompany her to go the market. I will not do it again.

In analyzing an expression, there is one thing that needs to be considered, namely context. The context includes age, gender, time, place, social status, and social distance. Expression (15) was used by the speaker because the speaker and hearer have equal social status. This utterance is incorrect. It should be "I am sorry. I really forget to come to our meeting." Besides social status, the aspects of social distance also influence the speaker to use the expression (15) because the speakers have known each other. In other words, they are acquaintances in terms of social distance. In the aspects of age, they are in the same age as friends. Meanwhile, the aspects of gender and time are not known in this context. Then, the speaker uses an intensification expression as s/he 
uses the word "really". In English, intensification is mainly achieved through the use of adverbs, such as terribly, really, so, awfully, please, etc. to upgrade the impact of the utterances/apologies on the hearers/offended. In other words, the speaker attempts to reduce the hearer's dissatisfaction because $\mathrm{s} / \mathrm{he}$ forgot the meeting twice. It means that the speaker shows regret and request for forgiveness for his/her mistake.

Expression (16) was used by the speaker with the same purpose (with \#15). That is, to show that the speaker forgets the meeting twice, but it sounds more different as s/he uses the word "darling". In this context, the speaker should not say 'darling' because it is just used for those people who have close relationship, such as parents and children, husband and wife, and lovers. This is inappropriate. The speaker should not have said 'darling' because they are just friends. It is also a kind of endearment expressions which indicates that the speaker has known the hearer well. In other words, they are intimates in terms of social distance. The endearment markers are often used when the speaker and hearer have close relationship in terms of social distance. In this case, the speaker does not only express the endearment expression, but also a compensatory action, such as "I will not do it again". It designates the speaker's responsibility to the hearer. The speaker embedded his/her apology expression with utterances aiming to minimize hearer's wrathfulness because of the speaker's carelessness.

\section{Offer of repair}

It is an expression used by the speaker attempting to repair or pay for the damage caused by his/her offense. Some utterances used are "I will pay for the damage", and "I promise to repair it."

Situation 13: The speaker has broken his/her friend's motorcycle.

(28) I am sorry. I get the accident and your motorcycle was broken because of us, but I promise to you. I will repair it soon may be tomorrow. I am sorry. Thank you, friend.

(29) Sorry bro, I have broken your motorcycle and I do not have money to repair it.

Expression (28) showed the speaker and hearer were equal in terms of social status. In addition to social status, the aspects of social distance also influence the speaker to use the expression (28) because the speaker uses the word "friend". It is a kind of solidarity markers which are often used when the speaker and the hearer have intimate relationship. This expression has a function as a flattery to diminish the hearer's wrathfulness. It shows that the speaker feels so close to the hearer. Thus, they are intimates in terms of social distance. In the last statement, the speaker expresses about a compensatory action by saying that the speaker will repair it soon. It is clear that the speaker shows his/her responsibility for that accident. Then, this situation takes place in a campus corridor. In the aspects of age, they are equal, while the aspects gender shows that they are males. The information of all these aspects was gotten by role play which was recorded and transcribed.

Moreover, expression (29) was used by the speaker with the same purpose (with \#28), that is, to show that the motorcycle was broken but it sounds more impolite as s/he uses the word "I do not have money to repair it". It indicates that the speaker does not care with his/her friend's motorcycle, it is a contradictory with expression (28) in which the speaker just says that the motorcycle has been broken by him/her and $\mathrm{s} / \mathrm{he}$ has not money to repair it. It designates that the speaker is irresponsible.

\section{Pragmatic transfer in apology strategies used by the students}

Pragmatic transfer refers to the influence of the first language (L1) in communication when the speakers use L2. Generally, pragmatic transfer occurs in two ways that is negative and positive transfer. A negative transfer causes an error in communication, while positive transfer or facilitation facilitates a communication. Further, Kasper (1992) proposes two kinds of pragmatic transfer, pragma-linguistic and socio-pragmatic transfer. Pragma-linguistic transfer occurs when the utterances from the L1 speakers are not applied insufficiently in L2 utterances. Meanwhile, the socio-pragmatic transfer occurs by the effects of social conditions in language using. It contains many variables, such as social status and social distance relationship. The following utterances produced by the respondents can be some examples on how the pragmatic transfer interferes the strategy in expressing apology.

Situation 9: A speaker and a friend have arranged to go to a concert together. He/she promised to buy the tickets. But, when his/her friend comes round in the evening of the concert, he/she realizes that he/she has forgotten to get the tickets 
(11) Ya Allah, really sorry. I forgot to buy it because I have something to do.

Situation 6: A speaker went to friend's apartment. Accidentally, he/she was broken friend's small ornament.

(12) Astaghfirullah, I am so sorry. I did not mean to break your ornament.

Situation 18: A speaker was late to submit an assignment.

(13) Assalamualaikum, excuse me sir. I have mistake with you because for being late to return your book.

Situation 25: A speaker was late to come to his/her friend's birthday party.

(14) Oh my friend, Hbd barakallah, sorry for being late, I am so sorry.

In examples (11, 12, 13 and 14), the underline words show the religiosity of the respondents because some Indonesian people tend to be religious, especially for Moslem and it often appears in their utterances. The utterances above "Ya Allah", "Astaghfirullahal'adzim", Assalamualaikum and Barakallah" are identical with Islam and often expressed by Moslem in their daily conversation. The utterance " $\mathrm{Ya}$ Allah" is almost the same with "Oh my God", while "Astaghfirullahal'adzim" is usually said when someone forget about something. However, the semantic meaning of "astaghfirullahal'adzim" is actually "asking for apology to God". Meanwhile, "Assalammualaikum" in the example (13) shows a greeting action which is expressed by the speaker when he/she meets to other Moslem, in this case the speaker wants to return lecturer's book. Then, the speaker looks his/her lecturer in corridor. So, that is why the speaker expresses greetings to start the conversation. Moreover, the word "Barakallah" is an expression to pray someone. Many Indonesian people have used it in their daily conversation. Those transfers have occurred by the effects of social conditions in language using.

Situation 23: A teacher asks the student to help her but at the same time the student has an appointment for job interview.

(15) I am sorry, miss. I cannot help you. I have job interview today once again I am sorry.

Situation 3: The speaker was late to return friend's book.

(16) I am so sorry, I was late to return it, guys. It is my indecency. $I$ am really sorry, sorry $I$ will return that book to you.

Situation 5: The speaker was bump into an older lady in department store. It caused her packages spilled all over the floor and her leg was hurt.
(17) I am sorry for my mistake. Let's go to the hospital. Once again please, please and please apologize me.

In examples $(15,16$, and 17), the underline utterances show the respondent was repeating their apology expressions. Sometimes, Indonesian people have used it in their daily conversation. It shows the regret to their offense, therefore, they repeat it in order to get the hearer's forgiveness. If it refers to target language culture, there was no repeating in expressing their regrets (Wouk, 2006,). Those transfers have occurred by the effects of social conditions in language using.

Situation 10: A speaker at a restaurant with friends. The waiter takes the speaker's order. A few minutes later, the speaker calls the waiter to change the order.

(18) I am sorry. I want to change my order

(19) Sorry may I change my order

Other pragmatic transfers were in the form of politeness expressions. As Syahri (2013) state pragmatic transfers can be a politeness motivated form where the ways the speaker initiated the request realizations. These expressions were the ways the subjects request to change the order. Many of them used Sorry or I am sorry instead of Excuse $m e$ as the attention getters, Meanwhile, native speakers of English would never start a request by saying, I $m$ sorry. In this context, the speaker should not say "sorry" as it is not needed because s/he does not do anything wrong. The uses of sorry here were inappropriate in the context in which the speakers did not mean to express sorrows or regrets. In fact, they transferred the term maaf in Indonesian to their requests. The natives of Indonesian often used the term maaf to avoid FTAs (termed by Brown \& Levinson, 1987) or at least to reduce the impositions to others when doing things with words.

Then, the other pragmatic transfers were a form of intensification expressions, such as 'please and really'. The student/speaker tends to use these words to upgrade the impact of the utterances/apologies on the hearers. These words are frequently used by the speaker. Furthermore, the endearment and solidarity expressions are often used when the speaker and hearer have close relationship in terms of social distance. Example of endearment expressions are " $M y$ beloved friend, I am really sorry for being late to return your book". It shows that the speaker and hearer have intimate relationship. The endearment markers are often used when the speaker and hearer have close relationship in 
terms of social distance. The speaker embedded his/her apology expression with utterances aiming to minimize hearer's wrathfulness because of the speaker's carelessness.

"I am so sorry darling, I really forget to inform you, actually I have promised with my mom". In this context, the speaker should not have said 'darling' because it is just used for those people who have close relationship such as parents and children, husband and wife, and lovers. This is inappropriate. The speaker should not have said 'darling' because they are just friends.

The other utterances are "My beautiful mom, I am sorry. I really forget to buy your order", "Sorry bro, I have been busy this morning", "Sorry, friend, I have broken your motorcycle". These examples are a form of solidarity expressions. The speaker embedded his/her apology expression with utterances aiming to minimize the hearer's wrathfulness because of the speaker's carelessness. It was done in order to maintain harmonious relationship between both of them. Furthermore, there is an honorific expression. It is usually used when the speaker has lower social status than the hearer, such as 'Sir, Mr., Boss, Miss and Professor. It is used to show the speaker's respect. For instance, 'I beg your pardon professor, it's my own mistake", "I am sorry Miss, I was late".

\section{CONCLUSION}

There are five apology strategies used in this study, that is, IFIDs, Taking on responsibility, Explanation or Account, Offer of repair, and Promise forbearance. The strategy of an expression of regret is the most frequent apology strategy used by the participants. Meanwhile, expression of self-deficiency and explanation are the other strategies which are used extensively. Furthermore, there are some different ways to express apology due to the social status and distance of the speakers and hearers. The speakers who have low social status tend to use polite strategy. It means that the speakers used appropriate and positive responses in three levels of social distance (intimate, stranger and acquaintance). Those people who have equal social status tend to use casual expression of apology. Meanwhile, those people who have high level of social status tend to use less polite expressions.

Then, the result of the combination realization in expressing apology strategies from the $6^{\text {th }}$ and $8^{\text {th }}$ semesters showed a similar pattern. It means that they used similar pattern of combination in expressing of apology strategy. After comparing and analyzing the data, the students of English Education Study Program of Islamic State University Raden Fatah Palembang use some pragmatic transfer in expressing apology. Pragmatic transfer occurred when the speakers are influenced by socio-cultural aspects like social status and distance. It would give a positive and negative effect in pragmatic transfer. In this case, the negative transfer was the most frequent pragmatic transfer used by the participants/students.

\section{ACKNOWLEDGEMENT}

I am deeply grateful to Professor Diemroh Ihsan, MA., Ph.D. and Professor Dr. Indawan Syahri, M.Pd. for their invaluable comments and suggestions on this article. All errors that remain are my own.

\section{REFERENCES}

Brown, P., \& Levinson. (1987). Some universals in language usage. Cambridge, UK: Cambridge University Press.

$\mathrm{Bu}$, J. (2012). A study of relationships between L1 pragmatic transfer and L2 proficiency. English Language Teaching, 5(1), 32-43. doi: 10.5539/elt.v5n1p32.

Cohen, A. D., \& Olshtain, E. (1993). The production of speech acts by EFL learners. TESOL Quarterly. 27(1), 33-56. doi: $10.1177 / 026553228500200103$.

Ellis, R. (2012). The study of second language acquisition. USA: Oxford University Press.

Gass, S. M., \& Slinker, L. (2001). Second language acquisition an introductionary course. Marwah, NJ: Lawrence Erlbaum Associates Publisher.

Goffman, E. (1971). Relations in public: Microstudies of the public order. New York, NY: Basic Books.

Holmes, J. (1989). Sex differences and apologies: One aspect of communicative competence. Applied Linguistics, 10(2), 194-213.

Istifci, I. (2009). The use of apologies by EFL learners. Journal of English Language Teaching, 2(3), 15-25.

Jebahi, K. (2011). Tunisian university students' choice of apology strategies in a discourse completion task. Journal of Pragmatics, 43(2), 648-662. doi: 10.1016/j.pragma.2010.09.008.

Kasper, G. (1992). Pragmatic transfer. Second Language Research, 8(3), 203-231. doi: $10.1177 / 026765839200800303$.

Moghaddam, M. M. (2012). Discourse structures of condolence speech act. Journal of English Language Teaching and Learning. 1(10), 106125. 


\section{Tiara Eliza}

Pragmatic transfer in apology employed by English education students of Islamic state university (UIN) Raden Fatah

Olshtain, E., \& Cohen, A. D. (1983). Apology: A speech act set. Sociolinguistics and Language Acquisition, 5(20), 18-35.

Qorina, D. (2012). Realization of apology strategies by English department students of Pekalongan University. Journal of Language and Literature, 7(1), 93-105.

Sugimoto, N. (1998). Norms of apology depicted in US American and Japanese literature on manners and etiquette. International Journal of Intercultural Relations, 22(3), 251-276.

Syahri, I. (2013). Resemblance of indirectness in politeness of EFL learners' request. Indonesian Journal of Applied Linguistics, 3(1), 148-165.

Syahri, I., \& Kadarisman, A. E. (2007). Pragmatic transfer in request realization. TEFLIN Journal, 18(2), 123-147.
Tamimi Sa'd, S. H., \& Mohammadi, M. (2014). A cross-sectional study of Iranian EFL learners' polite and impolite apologies. Journal of Language and Linguistic Studies, 10(1), 119136.

Tuncel, R. (2011). Apologizing and speech act realizations of Turkish EFL learners. Paper presented at International Conference on Management, Economics and Social Sciences (ICMESS) Bangkok. Retrieved from http://psrcentre.org/images/extraimages/121179 9.pdf.

Wouk, F. (2006). The language of apologizing in Lombok, Indonesia. Journal of Pragmatics, 38(6), 1457-1486. doi: 10.1016/j.pragma.2005.09.011. 